\title{
Immunological Risk Factors in Paediatric Kidney Transplantation
}

This article was published in the following Dove Press journal:

Research and Reports in Urology

Frank Friedersdorff ${ }^{1,2, *}$

Beatriz Banuelos-Marco ${ }^{1,2, *}$

Marie-Therese Koch ${ }^{1,3}$

Nils Lachmann ${ }^{1,4}$

Anna Bichmann (D) ${ }^{5,6}$

Kurt Miller ${ }^{1,2}$

Ricardo Gonzalez ${ }^{1,2}$

Dominik Müller ${ }^{1,3}$

Anja Lingnau ${ }^{1,2}$

'Charité - Universitätsmedizin Berlin, Corporate Member of Freie Universität Berlin, Humboldt-Universität zu Berlin, Berlin, Germany; ${ }^{2}$ Berlin Institute of Health, Clinic of Urology and Paediatric Urology, Berlin, Germany; ${ }^{3}$ Berlin Institute of Health, Department of Paediatric Gastroenterology, Nephrology and Metabolic Disorders, Berlin, Germany; ${ }^{4}$ Berlin Institute of Health, Institute of Transfusion Medicine, Berlin, Germany; ${ }^{5}$ Charité - Department of Anesthesiology and Operative Intensive Care Medicine, Campus Charité Mitte, Charité - Universitätsmedizin Berlin, Corporate Member of Freie Universität Berlin, Humboldt-Universität zu Berlin, Berlin, Germany; ${ }^{6}$ Berlin Institute of Health, Berlin, Germany

*These authors contributed equally to this work
Correspondence: Frank Friedersdorff Charité - Universitätsmedizin Berlin, Charitéplatz I, Berlin, 10117, Germany Tel +4930450615219

Email frank.friedersdorff@charite.de
Purpose: The aim of this study was to identify factors impacting recipient sensitization rates and paediatric renal transplant patient outcomes.

Patients and Methods: For this purpose, a retrospective analysis of 143 paediatric renal transplants was carried out. This included the evaluation of patient's and donor's demographic data, HLA mismatches, immunosuppressive therapy, rejection episodes, panel reactive antibody (PRA) and post-transplant lymphoproliferative disease (PTLD).

Results: The mean patient age at the point of transplant receival was 11.5 years with a mean follow up time of $9.33 \pm 5.05$ years. It was noted that graft survival rates for donors over 59 years had the worst outcome. HLA match did not show statistically significant influence on graft outcome. Graft survival for more than one biopsy-proven rejection was also significantly shorter ( $\mathrm{p}=0.008$ ). PRA were found in $28 \%$ of the recipient's post-transplantation and showed association with lower graft survival rates $(\mathrm{p}<0.001)$. In the present study, $22.7 \%(5 /$ 22) of the patients with EBV infections presented a PTLD.

Conclusion: In conclusion, good graft survival with reduced sensitization for future transplantations and minimize the risk of PTLD, can be ensured through a balance between donor age, HLA match and condition of the recipient should be sought. Furthermore, paediatric patients should preferably receive organs from donors between the age of 10 and 59. EBV infection could be a relevant factor for developing PTLD.

Keywords: paediatric transplantation, immunological risk factors, graft survival, immunosuppression, kidney transplant, donor statistic

\section{Introduction}

Renal transplantation (RTx) is the standard treatment for child and adolescent patients with end-stage renal disease (ESRD). In comparison to dialysis, RTx is proven to improve survival, ${ }^{1}$ growth ${ }^{2}$ and health-related quality of life (HRQOL). ${ }^{3}$ Although an improvement of graft survival of both living donor (LD) and deceased donor (DD) was observed, there are still differences. Graft survival in LD in general is better than in DD kidney transplantations. ${ }^{4-6}$

The underlying mechanisms (eg, HLA-matching) of this fact are still discussed. Marlais et al found that poorly HLA-matched LD transplant outcomes are superior to those of well HLA-matched DD transplant outcomes ${ }^{7}$ standing in contrary to Opelz et al findings. ${ }^{8}$ However, further maximizing graft function and graft survival in the paediatric population is vitally important, especially since graft survival for a second renal transplant has been shown to be significantly lower than that of first renal transplant irrespective of donor type. ${ }^{9,10}$ Furthermore, the question whether HLAmatching has an impact on sensitization rates and subsequent re-transplantation is 
still unresolved. ${ }^{11-13}$ While it is established that the HLA-DR mismatches are a risk factor for the development of posttransplant non-Hodgkin lymphoma. ${ }^{12}$ Several other factors with impact on paediatric transplant outcome are still under discussion, eg, donor and recipient age ${ }^{14,15}$ or blood transfusions. ${ }^{16}$

The aim of this study was to identify factors in our cohort which have an impact on recipient sensitization rates and consecutively patient- and transplant outcome after paediatric renal transplantation.

\section{Patients and Methods}

The data were collected and approved according to the guidelines of the institutional review board "Ethikkomission Charité" (Berlin, Germany) which is based on the ICH Guideline for Good Clinical Practice and the declaration of the World Medical Association from 1964 (Helsinki) in their current version. Patient consent for review of medical records was not required because all data were de-identified. The patient data were treated anonymously. In the present study, our database included anonymised retrospective paediatric renal transplantation data up to 21 years of recipient age from January 1997 to December 2013. We confirm that all organs were donated voluntarily with written informed consent, and this was conducted in accordance with the Declaration of Istanbul. Excluded were recipients transplanted at other centres, who received treatment at Charité. The entire follow-up was carried out at Charité hospital reducing the amount of missing data. The only external factors concerned the blood transfusions prior to transplantation at Charité in $10 \%$ of patients.

Information from the hospital archive, electronic medical records and EUROTRANSPLANT were used for data extraction. We evaluated patients and donors demographic data according to number of transplants, pre-transplant blood transfusions, transplant status (LD, DD, highurgency (HU)) immunosuppressive therapy, rejection episodes, biopsy-proven rejections and classification according to the Banff criteria 2013, ${ }^{17}$ PRA (solid phase assay, pretransplantation and in the follow-up assessments posttransplantation) and analysed data concerning the cases with PTLD, specifically infectious parameters such as Epstein-Barr virus (EBV) and Cytomegalovirus (CMV). Clinical rejections are defined as rejections that become clinically noticeable, for example elevation of creatinine.

The patients received Chemoprophylaxis for three months, in high-risk constellation for six months.
Furthermore, we analysed HLA-A, B and DR mismatch according to the EUROTRANSPLANT matching criteria, mismatches A, B, DR (reduced phenotype), the split matches in HLA-A+B+DR and the complete phenotype using HLA-A+B+C+DR+DQ.

Perioperative parameters were divided into intra- and postoperative. Intraoperative parameters focused on ischemia time and postoperative parameters included immunosuppressive therapy, graft function (patient without dialysis) and graft survival (non-censored for death). Graft function was measured at least annually using creatinine $(\mathrm{mg} / \mathrm{dl})$ and GFR $(\mathrm{mL} / \mathrm{min} / 1,73 \mathrm{~m} 2)$. Immunosuppressive therapy differed during the study time and was divided into two-time eras differed by era. Era 1 ranged from 1997 to 2005 and included maintenance immunosuppression with steroids, mycophenolate mofetil (MMF) and cyclosporine. Era 2 ranged from 2005 to 2013 and included an immunosuppression maintenance with steroids, MMF and Tacrolimus (Prednisolone $300 \mathrm{mg} / \mathrm{m}^{2}$ body surface area at the time of operation, from day one postoperatively $2 \times 30 \mathrm{mg} / \mathrm{m}^{2}$ body surface area and further reduction with end of therapy after one year post transplantation, Tacrolimus: $2 \times 5 \mathrm{mg} / \mathrm{m}^{2}$ body surface area per day and maintenance for LD $8-15 \mathrm{ng} / \mathrm{mL}$ and DD 10-15 ng/mL; MMF: $2 \times 500 \mathrm{mg} / \mathrm{m}^{2}$ body surface area per day, maximum $2 \mathrm{~g}$ per day; cyclosporine 2 x $250 \mathrm{mg} /$ $\mathrm{m}^{2}$ body surface area with maintenance levels of 200-150 $\mathrm{ng} / \mathrm{mL}$ for the first three months after transplantation followed by $150-80 \mathrm{ng} / \mathrm{mL}$ after three months post transplantation).

LD recipients received induction of immunosuppression (tacrolimus/MMF or cyclosporine/MMF) 48 hours before transplantation, DD recipients received in retransplantation cases treatment with basiliximab (approval in Germany from November 1998) at the time of transplantation and on day 4 after transplantation. Height age, height SD score, body mass index, body mass index SD score for height age was calculated using an onlinecalculator (www.4c-study.org-calculators).

Parametric data sets were statistically analysed using SPSS 22 (IBM Corporation, Somers, NY, USA) Nonparametric tests (Mann-Whitney $U$-test, Kruskal-Wallis test) were performed. The chi-square test was used to evaluate categorical variables. Predictors of graft survival were analysed by multivariable adjusted logistic regression. For binary variables, a logistic regression analysis was carried out. A p-value of less than 0.05 was considered statistically significant. 


\section{Results}

\section{Study Cohort}

Included were 143 paediatric renal transplant recipients from January 1997 to December 2013, 76 (53\%) boys and $67(47 \%)$ girls, mean age at transplantation was 11.5 years with a mean follow up time of $9.33 \pm 5.05$ years. As described in our previous study, ${ }^{10}$ the overall mortality was $5.6 \%$. The diagnoses of the recipients were also shown. ${ }^{10}$ PTLD (28\%) and children with myocarditis (28\%) embodying the main causes of death. Overall survival at one year was $99.3 \%$ followed by $95.2 \%$ at five years, $94.2 \%$ at ten years and $90.7 \%$ at 15 years. Graft survival rates were $92.2 \%, 85.5 \%, 71.1 \%$ and $62.1 \%$ after 1,5,10 and 15 years, respectively. The main cause of graft failure was chronic and acute rejection (AR) in $43 \%$ and $11.4 \%$ of cases.

\section{Living versus Deceased Donation}

LD transplantations were performed in 35 (24\%) of all cases. We were able to demonstrate a significant difference in graft function $(\mathrm{p}=0.039)$ between our LD and DD donor transplants. Nevertheless, Cox regression analysis showed no statistical significance for graft survival (log-rank: $\mathrm{p}=0.163$ ). The number of HLA-mismatches showed no differences between the LD and DD transplantation groups. We noted that recipients of LD kidneys were significantly older, taller and heavier $(p=0.007, p=0.010$ and $p=0.003$, respectively) than those of DD transplantations. Treatment with somatotropin (STH) was also less common in this cohort (LD: 32.4\%; DD: 59.8\%) ( $\mathrm{p}=0.01)$. Further, we discovered that patients receiving LD transplants had a shorter time on dialysis $(\mathrm{p}=0.005)$ as well as a shorter cold ischemia time $(p<0.001)$. For more detailed information about the differences between LD and DD can be reviewed in Table 1 .

\section{Donor Age}

Graft survival rates in different donor age groups were $(<10,10-39,40-59$ or $>60$ years $)$ different within the different age groups (log rank $\mathrm{p}<0.001)$. Graft survival was best in the donor age groups 10-39 years (Figure 1).

\section{Rejections}

Out of 143 recipients, 63 (44\%) had one or more episodes of clinical rejection. Biopsy proven rejections were found in $38.5 \%(55 / 143)$ of the children and classified according to the Banff criteria. Acute rejections (AR) were the most frequent with $64.7 \%$, followed by Banff Borderline (BB)
(26.5\%) and chronic rejections (CR) (8.8\%). Both clinical and biopsy-proven rejections had a strong influence on graft function and graft survival. Within the group with graft failure, the incidence of rejection episodes was significantly higher $(1.89 \pm 1.91$ vs $0.59 \pm 0.883, \mathrm{p}<0.001)$. This also could be confirmed with biopsy-proven rejections $(1.54 \pm 1.63$ vs $0.45 \pm 0.75, \mathrm{p}<0.001)$. Graft survival for more than one biopsy-proven rejection was also significantly shorter (logrank $\mathrm{p}=0.008$ ) compared to the group of children with one or no biopsy-proven rejection. All rejections were t-cell mediated. Clinical rejections and biopsy-proven rejections for different parameters are shown in Table 2.

Further, rejections can be analysed in the context of varying immunosuppressive therapy. Since 2006, tacrolimus became a crucial part of the immunosuppressive therapy and hence allows us to split our patient cohort into two-time eras. We immediately noted the difference in incidences of rejections between the two-time eras, showing a significantly lower rate in Era $2(0.23 \pm 0.56, \mathrm{p}<0.001)$ in comparison to Era $1(1.28 \pm 1.49, \mathrm{p}<0.001)$. This could also be found for biopsy-proven rejections: Era 1 with 0.98 \pm 1.26 vs Era $20.23 \pm 0.55(\mathrm{p}<0.001)$. Tacrolimus therapy also showed to be significant within the two-time groups. In the group that did not receive tacrolimus, there was 1.20 \pm 1.32 in Era 1 compared to $0.62 \pm 1.32$ in Era $2(\mathrm{p}=0.001)$ with tacrolimus and for biopsy-proven rejections we saw a decrease from $1.00 \pm 1.28$ to $0.43 \pm 0.87$ ( $\mathrm{p}=0.003$ ).

Mean donor age with $38.62 \pm 19.39$ years was higher in the group of patients with rejections than in the group without rejections $30.25 \pm 18.53$ years $(\mathrm{p}=0.003)$. Younger recipients $(0-15$ years) had more biopsy-proven rejections $(0.79 \pm 1.15)$ than older recipients $(16-21$ years) $(0.46 \pm 1.04, \mathrm{p}=0.061)$. The mean number of clinical rejections was lower for first transplantations $(0.82 \pm 1.26)$ in comparison to second transplantation $(1.93 \pm 1.71, \mathrm{p}=0.009)$. This also could be shown for biopsy-proven rejections ( $0.62 \pm 0.99$ vs $1.35 \pm 1.66$, $\mathrm{p}=0.013$ ).

After analysing the rejections in the group of patients with PRA pre-transplantation, we found that the mean number of biopsy-proven rejections was lower in the group without PRA than in the group without PRA (0.63 \pm 1.03 vs $1.24 \pm 1.55, \mathrm{p}=0.048$ ).

\section{HLA Matches and Panel Reactive Antibodies}

We analysed according to the EUROTRANSPLANT matching criteria, mismatches A, B, DR (reduced 
Table I Demographic Data and Differences Between the LD and DD Population

\begin{tabular}{|c|c|c|c|}
\hline Variables & $\begin{array}{l}\text { LD }(\mathbf{N}=35) \\
\text { Mean } \pm S D\end{array}$ & $\begin{array}{l}\text { DD }(\mathrm{N}=108) \\
\text { Mean } \pm S D\end{array}$ & p-value \\
\hline \multicolumn{4}{|l|}{ Donor } \\
\hline Height $(\mathrm{cm})$ & $173.50 \pm 8.56$ & $153.54 \pm 30.34$ & $0.002 *$ \\
\hline Weight (kg) & $76.93 \pm 16.59$ & $56.49 \pm 28.56$ & $<0.001 *$ \\
\hline Age (years) & $41.23 \pm 10.62$ & $30.73 \pm 21.16$ & 0.069 \\
\hline \multicolumn{4}{|l|}{ Recipient } \\
\hline Height (cm) & $|45.54 \pm 24.8|$ & $134.6 \pm 25.27$ & $0.010^{*}$ \\
\hline Weight (kg) & $43.95 \pm 18.88$ & $33.39 \pm 15.20$ & $0.003 *$ \\
\hline Age (years) & $12.19 \pm 5.37$ & $9.62 \pm 4.63$ & $0.007 *$ \\
\hline \multicolumn{4}{|l|}{ Time (days) } \\
\hline $\begin{array}{l}\text { Post-operative in- } \\
\text { hospital stay }\end{array}$ & $27.55 \pm 9.15$ & $35.24 \pm 14.72$ & $0.002 *$ \\
\hline $\begin{array}{l}\text { Follow-up in- } \\
\text { hospital stay }\end{array}$ & $30.52 \pm 46.61$ & $52.51 \pm 55.67$ & $0.003 *$ \\
\hline $\begin{array}{l}\text { Time on dialysis } \\
\text { (months) }\end{array}$ & $9.57 \pm 9.30$ & $18.63 \pm 17.05$ & $0.005^{*}$ \\
\hline $\begin{array}{l}\text { Pre-transplantation } \\
\text { STH-therapy (\%) }\end{array}$ & 32.4 & 59.8 & $0.005^{*}$ \\
\hline $\begin{array}{l}\text { Duration of } \\
\text { treatment (months) }\end{array}$ & $5.55 \pm 13.56$ & $19.74 \pm 28.69$ & $0.001 *$ \\
\hline $\begin{array}{c}\text { Delayed graft } \\
\text { function DGF (\%) }\end{array}$ & 3.1 & 26.8 & $0.004^{*}$ \\
\hline \multicolumn{4}{|l|}{ Mismatches } \\
\hline $\begin{array}{l}\text { HLA-A, B, DR } \\
(n=142)\end{array}$ & $2.37 \pm 1.41$ & $2.60 \pm 1.31$ & 0.82 \\
\hline $\begin{array}{l}\text { Split HLA-A, B, DR } \\
(n=142)\end{array}$ & $2.43 \pm 1.42$ & $2.78 \pm 1.35$ & 0.84 \\
\hline $\begin{array}{l}\text { Split HLA-A, B, C, } \\
\text { DR, DQ }(n=110)\end{array}$ & $4.13 \pm 2.33$ & $4.25 \pm 2.05$ & 0.92 \\
\hline $\begin{array}{l}\text { Cold ischemia time } \\
\text { (minutes) }\end{array}$ & $|53.47 \pm 5| .86$ & $869.28 \pm 316.5 \mid$ & $<0.001^{*}$ \\
\hline
\end{tabular}

Note: *Statistically significant.

Abbreviations: LD, living donor; DD, deceased donor.

phenotype), the split matches in $\mathrm{HLA}-\mathrm{A}+\mathrm{B}+\mathrm{DR}$ and the complete phenotype using HLA-A+B+C+DR+DQ. Mean number of mismatches was for $\mathrm{A}, \mathrm{B}$, DR (reduced phenotype) $2.54 \pm 1.33$, the split matches in HLA-A+B+DR $2.69 \pm 1.37$ and the complete phenotype using HLA-A+B $+\mathrm{C}+\mathrm{DR}+\mathrm{DQ} 4.22 \pm 2.12$, which can further be seen in Table 3. The number of HLA mismatches did not show any statistically significant association either on transplant function or on graft survival. Cox regression analysis on all three types of mismatches proved that an increase of HLA mismatches did not correlate with lower graft survival. Also, the number of HLA mismatches had no impact on the frequency of rejection

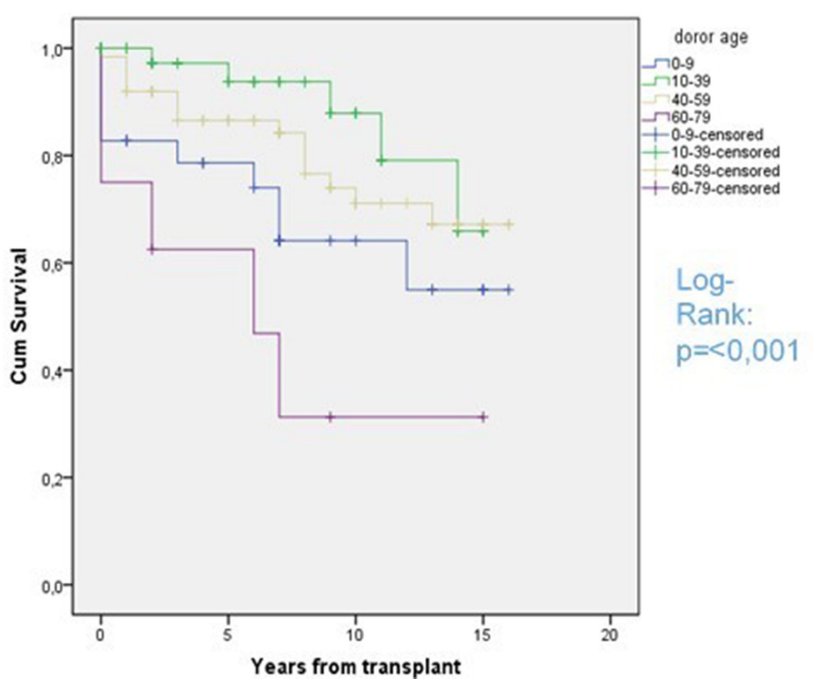

Figure I Graft survival rates according to donor age groups. Shown here LD and DD analyzed together, in the DD donor group there was no one over 70 years of age and in the LD group no donor under 19 years of age.

episodes. Interestingly, the number of mismatches for the complete phenotype was increasing over time (Era 1 total MM 3.85 \pm 2.09 , Era 2 4.75 $\pm 2.42, \mathrm{p}=0.077$ ).

More than $14 \%(21 / 143)$ of the children were tested positive for PRA before transplantation. Mean maximum activity was $36.2 \pm 26.5 \%$. Statistical association with lower graft survival rates could not be identified $(\mathrm{p}=0.636)$. PRA were found in 40/143 (28\%) patients post-transplantation (mean activity $46.4 \pm 28.8 \%$ ) and showed association with lower graft survival rates $(\mathrm{p}<0.001)$. To identify other influencing factors on PRA we divided the patients into two groups. Group 1 receiving the first and group 2 receiving a re-transplant. The level of PRA showed in these groups significant differences. Patients who received the first transplant showed significantly less PRA pre- and posttransplantation $(\mathrm{p}<0.001)$. All above data is summarized in Table 3.

The outcome parameter graft function, graft survival and mortality were analysed in a multivariable analysis with different variables (Table 4).

\section{Blood Transfusions}

Sixty percent (66/110) of the transplanted children received one or more blood transfusions pre-transplantation. There was no significant influence on patient or graft survival ( $p=0.350$, log-rank: $p=0.082$ ). Within the group of children who received blood transfusions prior to transplantation, we found a higher incidence of PRA $(p=0.010)$. 
Table 2 Clinical Rejections and Biopsy Proven Rejections for Different Parameters

\begin{tabular}{|c|c|c|c|c|}
\hline $\begin{array}{l}\text { Parameters } \\
\text { Graft function }\end{array}$ & \multicolumn{2}{|c|}{ Clinical Rejections Mean \pm SD p-value } & \multicolumn{2}{|c|}{ Biopsy Proven Rejections Mean \pm SD p-value } \\
\hline $\begin{array}{l}\text { Graft function } \\
\text { Graf failure } \\
\text { Graft function } \\
\text { Graft survival }\end{array}$ & $\begin{array}{l}I .89 \pm 1.91 \\
0.59 \pm 0.88 \\
\text { Log rank } p=0.008^{*}\end{array}$ & $0.002 *$ & $\begin{array}{l}1.54 \pm 1.63 \\
0.45 \pm 0.75 \\
\text { Log rank } p<0.001 *\end{array}$ & $0.011 *$ \\
\hline $\begin{array}{l}\text { Transplantation no. } \\
\text { First transplantation } \\
\text { Second transplantation }\end{array}$ & $\begin{array}{l}0.82 \pm \mid .26 \\
|.93 \pm| .7 \mid\end{array}$ & $0.009 *$ & $\begin{array}{l}0.62 \pm 0.99 \\
1.35 \pm 1.66\end{array}$ & $0.013^{*}$ \\
\hline $\begin{array}{l}\text { Transplant era } \\
\text { 1997-2005 } \\
2006-2013\end{array}$ & $\begin{array}{l}1.28 \pm 1.49 \\
0.23 \pm 0.5\end{array}$ & $\mathrm{p}<0.00 \mathrm{I}^{*}$ & $\begin{array}{l}0.98 \pm 1.26 \\
0.23 \pm 0.55\end{array}$ & $\mathrm{P}<0.00 I^{*}$ \\
\hline $\begin{array}{l}\text { Immunosuppression } \\
\text { Tacrolimus } \\
\text { No tacrolimus }\end{array}$ & $\begin{array}{l}0.62 \pm 1.32 \\
1.20 \pm 1.32\end{array}$ & $0.001 *$ & $\begin{array}{l}0.43 \pm 0.87 \\
1.00 \pm 1.28\end{array}$ & $0.003 *$ \\
\hline $\begin{array}{l}\text { Donor age (mean age) } \\
\text { Rejection yes } \\
\text { No rejections }\end{array}$ & $\begin{array}{l}38.62 y \pm 19.4 y \\
30.25 y \pm 18.5 y\end{array}$ & $0.013 *$ & $\begin{array}{l}39.53 y \pm 19.9 y \\
30.04 y \pm 18.2 y\end{array}$ & $0.003 *$ \\
\hline $\begin{array}{l}\text { Recipient age } \\
0-15 \\
|6-2|\end{array}$ & n. a. & & $\begin{array}{l}0.79 \pm 1.15 \\
0.46 \pm 1.04\end{array}$ & 0.061 \\
\hline $\begin{array}{l}\text { Living vs deceased donation } \\
\text { Mean no. rejections LD } \\
\text { Mean no. rejections DD }\end{array}$ & $\begin{array}{l}0.61 \pm 1.06 \\
1.02 \pm 1.41\end{array}$ & 0.093 & $p=0.143$ & \\
\hline $\begin{array}{l}\text { PRA pre-transplant } \\
\text { PRA yes } \\
\text { PRA no }\end{array}$ & $p=0.121$ & & $\begin{array}{l}1.24 \pm 1.55 \\
0.63 \pm 1.03\end{array}$ & $0.048 *$ \\
\hline $\begin{array}{l}\text { PRA post-transplant } \\
\text { PRA yes } \\
\text { PRA no }\end{array}$ & $\mathrm{P}=0.092$ & & $\begin{array}{l}1.15 \pm 1.53 \\
0.55 \pm 0.89\end{array}$ & 0.057 \\
\hline $\begin{array}{l}\text { Transfusions pre-transplant } \\
\text { Yes } \\
\text { No }\end{array}$ & n. a. & & $\begin{array}{l}0.81 \pm 1.18 \\
0.73 \pm 1.17\end{array}$ & 0.692 \\
\hline
\end{tabular}

Note: *Statistically significant.

\section{Post-Transplant Lymphoproliferative Disease}

In $4.5 \%(6 / 132)$ of the patients PTLD developed, and 2/6 of them died. PTLD is a significant risk factor for death in our cohort $(\mathrm{p}=0.003)$. All the recipients were EBV negative before transplantation. In 5 of 6 patients suffering from PTLD, an infection with EBV was detected and consequently treated with intravenous Foscavir.

The presentation of PTLD in our patients was as follows: Intrathoracic B-Cell Lymphoma, a high-grade abdominal B Cell lymphoma Burkitt-Typ (Translocation
8/14), an ileal large cell diffuse non Hodgkin lymphoma, an EBV associated lymphoproliferative disorder of the tongue, a subcutaneous PTLD of the calf muscle and a EBV associated malignant B cell lymphoma of the eyelid. The immunosuppression before diagnosis was performed by a combination of glucocorticoid, MMF and cyclosporin $(5 / 6)$ or tacrolimus (1/6). Two patients suffered a rejection that was successfully treated without affecting the graft function. Half of the patients (3/6) had a living donor transplant. Mean time from transplantation to diagnosis was 25.2 (range 4-72) months. Mean age at the time of diagnosis was $12.7 \pm 6.7$ (range 5-19) years. 
Table 3 Patients Divided into Two Groups According to First or Re-Transplantation

\begin{tabular}{|c|c|c|c|}
\hline Variables & First-Transplantation $(n=\mid 23)$ Mean \pm SD & Re-Transplantation $(n=20)$ Mean \pm SD & p-value \\
\hline $\begin{array}{l}\text { PRA pre-TX } \\
\text { (Amount in \%) } \\
\text { (Level in \%) }\end{array}$ & $\begin{array}{l}5.7 \\
1.47\end{array}$ & $\begin{array}{c}70 \\
28.95\end{array}$ & $\begin{array}{l}<0.00 I^{*} \\
<0.00 I^{*}\end{array}$ \\
\hline $\begin{array}{l}\text { PRA after-TX } \\
\text { (Amount in \%) } \\
\text { (Level in \%) }\end{array}$ & $\begin{array}{l}22.8 \\
9.90\end{array}$ & $\begin{array}{c}60 \\
31.95\end{array}$ & $\begin{array}{c}0.00 I^{*} \\
<0.00 I^{*}\end{array}$ \\
\hline $\begin{array}{l}\text { Biopsy proven rejections } \\
\text { (Number) }\end{array}$ & $0.62 \pm 0.99$ & $1.35 \pm 1.66$ & $0.013^{*}$ \\
\hline $\begin{array}{l}\text { Blood transfusion pre-TX } \\
\text { (Amount in \%) } \\
\text { (Number) }\end{array}$ & $\begin{array}{c}55.3 \\
11.40 \pm 28.94\end{array}$ & $\begin{array}{c}87.5 \\
16.13 \pm 32.46\end{array}$ & $\begin{array}{l}0.015^{*} \\
0.002 *\end{array}$ \\
\hline
\end{tabular}

Note: *Statistically significant.

Abbreviation: TX, transplantation.

\section{Epstein-Barr Virus and Cytomegalovirus}

EBV infections occurred in 22 (15.4\%) patients. This small group of paediatric patients with EBV infections showed no statistical association with the graft failure or overall mortality of our series $(\mathrm{p}=0.772 / \mathrm{p}=0.980)$. However, EBV infection was a relevant factor for developing a PTLD $(\mathrm{p}<0.001)$. In the present study, 22.7\% (5/ 22) of the patients with EBV infections presented a PTLD, being only one patient EBV negative of those who developed PTLD. Analysing the data on this patient we found an above average amount of mismatches (HLA-A, B, DR: 4, split-HLA-A, B, DR: 4 and split-HLA-A, B, C, DR, DQ: 6) along with an immunosuppression with glucocorticoid, MMF and cyclosporine, no rejections, donor CMV positive, recipient $\mathrm{CMV}$ negative. CMV infection in our cohort was neither significantly associated with an increased risk of graft loss $(\mathrm{p}=0.332)$ nor with development of PTLD $(\mathrm{p}=0.81)$.

\section{Discussion}

The key features of this study analysis are that it first shows a large number of patients under 21 years of age with along follow up within a single institution. Patient and graft survival rates are similar to other reports in the literature and match the current benchmarks. ${ }^{4}$ The present data shows that LD kidney transplantation ensures for the children the best possible outcome after renal transplantation regarding graft function and a trend towards better graft survival as well as other factors, including length of hospital stay and time on dialysis (Table 1). Looking at the
LD/DD recipient demographics, also a significant difference was that the LD recipient was older and in a better physical state considering age-corrected height and weight. We noticed that LD recipients had a significant better graft function compared to DD recipients. This can also be found in the literature; even paper about this topic is rare. ${ }^{18} \mathrm{~A}$ reason for this finding could be the shorter cold ischemia time in living donor setting.

However, not every child will find a living donor and the likelihood of receiving a subsequent transplant is high, which makes it particularly important to identify mechanisms of immunization and influencing factors on patient and transplant outcomes.

The best outcomes were achieved with donors between 10 and 59 years of age (see Figure 1). Data from the European Society for Paediatric Nephrology - Registry study suggest that donations from older living donors (50-75 years) provide excellent graft outcomes in all paediatric recipients. ${ }^{15}$ The data were analysed for first kidney transplantations. ${ }^{15}$

However, the number of rejection episodes is the main factor determining graft survival. Factors, influencing episodes of rejection included immunosuppression regiment, donor age, recipient age, presence of PRA and number of transplants. Since the introduction of tacrolimus, we could show a significant decrease of rejections in our cohort. Interestingly, the donor age had an influence on the number of rejections as well as on the transplant outcome in our cohort, which was also reported in other research studies. ${ }^{19}$ Further studies are required to review the effect 
Table 4 Multivariate Analysis of Outcome Parameter Graft Function, Graft Survival and Mortality

\begin{tabular}{|c|c|c|c|}
\hline Variables & Graft Function p-value & Graft Survival p-value & Recipient Mortality p-value \\
\hline \multicolumn{4}{|l|}{ Donor/recipient } \\
\hline Transplantation era & $<0.00 I^{*}$ & $<0.001 *$ & 0.113 \\
\hline Mismatches & 0.683 & 0.186 & 0.845 \\
\hline Body weight ratio & 0.547 & n. a. & 0.069 \\
\hline \multicolumn{4}{|l|}{ Donor } \\
\hline Hypotension & 0.027 & 0.148 & 0.53 \\
\hline Age & 0.071 & $0.004^{*}$ & 0.062 \\
\hline Sex & 0.11 & n. a. & 0.319 \\
\hline \multicolumn{4}{|l|}{ Recipient } \\
\hline Previous operations & 0.227 & n. a. & 0.79 \\
\hline Transfusions & 0.153 & 0.082 & 0.35 \\
\hline Age & 0.159 & n. a. & 0.745 \\
\hline Sex & 0.551 & n. a. & 0.364 \\
\hline Residual urine & 0.1 & n. a. & 0.257 \\
\hline Re-transplantation & $0.004 *$ & $0.003^{*}$ & $0.048 *$ \\
\hline Pre-emptive transplantation & 0.35 & 0.199 & 0.352 \\
\hline Type of dialysis & 0.538 & n. a. & 0.542 \\
\hline Duration of dialysis & 0.425 & n. a. & 0.423 \\
\hline En-bloc transplantation & 0.335 & 0.6 & $0.45 I$ \\
\hline Warm ischemia time & 0.589 & n. a. & 0.795 \\
\hline Cold ischemia time & $0.017^{*}$ & $0.047^{*}$ & 0.899 \\
\hline Rejections episodes & $<0.00 I^{*}$ & $0.008^{*}$ & n. a. \\
\hline Biopsy rejections & 0.067 & $<0.001$ & n. a. \\
\hline Initial function & $0.003 *$ & $0.006^{*}$ & 0.793 \\
\hline Hypertension & 0.11 & $0.019 *$ & 0.681 \\
\hline Time of hospitalisation & $<0.00 I^{*}$ & n. a. & 0.529 \\
\hline
\end{tabular}

Note: *Statistically significant.

of donor age in the era of tacrolimus on long-term graft survival.

Presence of PRA pre-transplantation was significantly associated with increased episodes of biopsy-proven rejections. PRA in this context is an unspecific marker of sensitisation of the recipient. Whether donor-specific antibodies can predict the likelihood of rejections and impact on transplant outcome in our paediatric population is currently evaluated. This stands in concurrence with studies previously published by others. ${ }^{20,21}$ PRA also were more frequently prevalent in the group of children receiving a second organ transplant and consequently correlate with a higher incidence of rejections. Although blood transfusions in our data showed no relationship with graft function or survival, we could show that transfusions were a contributing factor to the development of PRA.

The HLA-matching data in our cohort could neither show a difference in graft function and survival. This might be due to the relatively low number of mismatches in all groups and to the fact that in the second Era the total amount of mismatches was higher than in the previous years, which might reflect the genuine problem of keeping the time on the waiting list relatively short and find an acceptable HLA match. Opelz et al reported that graft survival of kidneys from deceased donors with 0 to 1 HLA mismatches in paediatric kidney transplantation compares favourably with graft survival of grafts from living donors with 4 to 6 HLA mismatches. ${ }^{8}$ In our cohort, the differences between CD and LD were not large. We found a significant difference in graft function, but not in graft survival. In our opinion, there is not only one reason for this negative finding. The homogenous and low level of mismatches and maybe the different group size could be an explanation. Even though HLAmatching had no impact on transplant outcome in our cohort, an increase in HLA sensitization by HLA mismatching is concerning since it might lead to significant delay or preclusion from future re-transplantation. Gralla 
et al could show that HLA-DR mismatches in the first transplantation leads to higher degrees of sensitisation, reduced re-transplantation rates, and longer time to transplant, if re-transplant is achieved. ${ }^{13}$ They also found evidence of an effect of initial DR mismatching on retransplant graft outcomes. Further, HLA sensitisation is strongly associated with poorer re-transplant outcome ${ }^{13}$ and it is established that at the HLA-DR mismatches increase the risk factor for the development of posttransplant non-Hodgkin lymphoma. ${ }^{12}$ In our data, we could establish a significance between EBV infections and development of PTLD.

Lastly, we could demonstrate the problem of immunisation of the recipient in our data comparing first transplantations to re-transplantations. The amount and levels of PRA were significantly higher in the re-transplantation group. Consecutively, the number of rejections was higher in the group of children receiving a re-transplantation.

We conclude that significant progress in paediatric renal transplantation has been made in the last decades mostly due to improvement of immunosuppression. To ensure good graft survival while reducing sensitisation for future renal transplants and minimising the risk of PTLD, a balance between donor age, HLA match and condition of the recipient should be sought. We also recommend that organs from donors between 10 and 59 years of age should be allocated to paediatric patients. Transplantations with two HLA-DR mismatches should not be carried out, in order to reduce the risk of posttransplant non-Hodgkin lymphoma. EBV infection could be a relevant factor for developing PTLD.

\section{Acknowledgment}

The authors acknowledge support from the German Research Foundation (DFG) and the Open Access Publication Fund of Charité - Universitätsmedizin Berlin.

\section{Author Contributions}

Conceptualization, M-T.K. and A.L.; data curation, M-T. K. and N.L.; writing, F.F. and B.B-M.; supervision, R.G., F.F., K.M. and D.M.; review and editing, A.B., N.L. All authors made substantial contributions to conception and design, acquisition of data, or analysis and interpretation of data; took part in drafting the article or revising it critically for important intellectual content; agreed to submit to the current journal; gave final approval of the version to be published; and agree to be accountable for all aspects of the work.

\section{Disclosure}

Dr Nils Lachmann reports personal fees from BmT $\mathrm{GmbH}$, outside the submitted work. The authors have no other conflicts of interest to disclose.

\section{References}

1. McDonald SP, Craig JC. Long-term survival of children with end-stage renal disease. $N$ Engl J Med. 2004;350(26):2654-2662. doi:10.1056/NEJMoa031643

2. Nissel R, Brázda I, Feneberg R, et al. Effect of renal transplantation in childhood on longitudinal growth and adult height. Kidney Int. 2004;66(2):792-800. doi:10.1111/j.1523-1755.2004. 00805.x

3. Goldstein SL, Graham N, Burwinkle T, et al. Health-related quality of life in paediatric patients with ESRD. Pediatr Nephrol. 2006;21 (6):846-850. doi:10.1007/s00467-006-0081-y

4. Smith JM, Martz K, Blydt-Hansen TD. Pediatric kidney transplant practice patterns and outcome benchmarks, 1987-2010: a report of the North American Pediatric Renal Trials and Collaborative Studies. Pediatr Transplant. 2013;17(2):149-157. doi:10.1111/ petr.12034

5. Latin American Pediatric Nephrology Association (ALANEPE), Latin American Pediatric Renal Transplant Cooperative Study. Latin American Registry of Pediatric Renal Transplantation 2004-2008. Pediatr Transplant. 2010;14(6):701-708. doi:10.1111/ j.1399-3046.2010.01331.x

6. ERA-EDTA-Registry. Department of Medical Informatics, Amsterdam University Medical Centers, location AMC. Annual Report 2011. Available from: http://www.era-edta-reg.org/files/annualreports/pdf/ AnnRep2011.pdf. Accessed February 16, 2021.

7. Marlais M, Hudson A, Pankhurst L, et al. Living donation has a greater impact on renal allograft survival than HLA matching in pediatric renal transplant recipients. Transplantation. 2016;100:2717-2722. doi:10.1097/TP.0000000000001159

8. Opelz G, Döhler B, Middleton D, et al. HLA matching in pediatric kidney transplantation: HLA poorly matched living donor transplants versus HLA well-matched deceased donor transplants. Transplantation. 2017;101(11):2789-2792. doi:10.1097/TP.00000 00000001811

9. Magee JC, Barr ML, Basadonna GP, et al. Repeat organ transplantation in the United States, 1996-2005. Am J Transplant. 2007;7 (s1):1424-1433. doi:10.1111/j.1600-6143.2007.01786.x

10. Friedersdorff F, Koch T-M, Banuelos-Marco B, et al. Long-term follow-up after paediatric kidney transplantation and influence factors on graft survival: a single-centre experience of 16 years. Urol Int. 2018;100(3):317-321. doi:10.1159/000487195

11. Opelz G, Dohler B. Pediatric kidney transplantation: analysis of donor age, HLA match, and posttransplant non-Hodgkin lymphoma: a collaborative transplant study report. Transplantation. 2010;90 (3):292-297. doi:10.1097/TP.0b013e3181e46a22

12. Opelz G, Dohler B. Impact of HLA mismatching on incidence of posttransplant non-hodgkin lymphoma after kidney transplantation. Transplantation. 2010;89(5):567-572. doi:10.1097/TP.0b013e3181 c69855

13. Gralla J, Tong S, Wiseman AC. The impact of human leukocyte antigen mismatching on sensitization rates and subsequent retransplantation after first graft failure in pediatric renal transplant recipients. Transplantation. 2013;95(10):1218-1224. doi:10.1097/ TP.0b013e318288ca14

14. Trnka P, McTaggart SJ, Francis A. The impact of donor/recipient age difference and HLA mismatch on graft outcome in pediatric kidney transplantation. Pediatr Transplant. 2018;22(7):e13265. doi:10.1111/ petr. 13265 
15. Chesnaye NC, van Stralen KJ, Bonthuis M, et al. The association of donor and recipient age with graft survival in paediatric renal transplant recipients in a European Society for Paediatric Nephrology/ European Renal Association-European Dialysis and Transplantation Association Registry study. Nephrol Dial Transplant. 2017;32 (11):1949-1956. doi:10.1093/ndt/gfx261

16. Verghese P, Gillingham K, Matas A, et al. Post-transplant blood transfusions and pediatric renal allograft outcomes. Pediatr Transplant. 2016;20(7):939-945. doi:10.1111/petr.12788

17. Haas M. An updated Banff schema for diagnosis of antibody-mediated rejection in renal allografts. Curr Opin Organ Transplant. 2014;19(3):315-322. doi:10.1097/MOT.000000000000 0072
18. Sözen H, Dalgic A, Karakayali H, et al. Renal transplantation in children. Transplant Proc. 2006;38(2):426-429. doi:10.1016/j. transproceed.2006.01.014

19. Woo YM, Gill JS, Johnson N, et al. The advanced age deceased kidney donor: current outcomes and future opportunities. Kidney Int. 2005;67(6):2407-2414. doi:10.1111/j.1523-1755.2005.00348.x

20. Wiebe C, Gibson IW, Blydt-Hansen TD, et al. Rates and determinants of progression to graft failure in kidney allograft recipients with de novo donor-specific antibody. Am J Transplant. 2015;15(11):2921-2930. doi:10.1111/ajt.13347

21. Gulleroglu K, Baskin E, Bayrakci US, et al. Antibody-mediated rejection and treatment in pediatric patients: one center's experience. Exp Clin Transplant. 2013;11(5):404 407. doi:10.6002/ect.2012.0242

\section{Publish your work in this journal}

Research and Reports in Urology is an international, peer-reviewed, open access journal publishing original research, reports, editorials, reviews and commentaries on all aspects of adult and pediatric urology in the clinic and laboratory including the following topics Pathology, pathophysiology of urological disease; Investigation and treatment of urological disease; Pharmacology of drugs used for the treatment of urological disease. The manuscript management system is completely online and includes a very quick and fair peer-review system, which is all easy to use. Visit http://www.dovepress.com/ testimonials.php to read real quotes from published authors. 